Interactive comment on "The advective Brewer-Dobson circulation in the ERA5 reanalysis: variability and trends" by Mohamadou Diallo et al.

Mohamadou Diallo et al.

m.diallo@fz-juelich.de

Received and published: 8 February 2021

Please find enclosed the responses!

Interactive comment on Atmos. Chem. Phys. Discuss., https://doi.org/10.5194/acp-2020-881, 2020. 
Answer to Reviewer's comments on "The advective Brewer-Dobson cir-
culation in the ERA5 reanalysis: climatology, variability and trends" by Mohamadou Diallo et al.

We are submitting our revised article titled "'The advective Brewer-Dobson circulation in the ERA5 reanalysis climatology, variability and trends". We thank the two Reviewers for their detailed and well thought-out comments, which helped to significantly improve the paper. We have made substantial changes to the manuscript in order to thoroughly address the Reviewers' suggestions and comments. Main changes concern:

- The calculation of residual circulation from wave drag using the downward control principle, as suggested by Reviewer \#1, a new figure showing these results and the related discussion.

- Addition of statistical significance using Student's t-test to the differences as suggested by Reviewer \#1

- Addition of information related to S-RIP and references.

- Re-calculation of the RCTT using the $\mathrm{w}^{*}$ instead of heating rates for 2010-2018

- rephrasing of several paragraphs in order to clarify the manuscript.

With these changes, we are convinced that the paper has been significantly improved and is highly relevant for a wide-ranging journal like Atmospheric Che
to all reviewers comments and suggestions.

Reviewers comments are in bold, followed by our respective replies. Changes in the manuscript are in blue, allowing them to be tracked easily.

Kindegards,

Anonymous Referee \#2:

\section{General comments:}

1. - While the detailed comparison between ERA5 and ERA-interim is very useful, it would also help mentioned that previous work has shown ERA-interim to be to have too strong upwelling. but it would be nice to know more. Since this paper is part of the S-RIP special issue, it would the

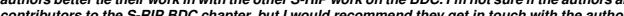
of that chapter and have some content on the broader context of reanalysis representations of the BDC.

We thank the Reviewer for this thoughtful suggestions. We are involved in several S-RIP chapter, including the S-RIP BDC chapter 5 . We have enhanced the discussion about the comparison to other reanalyses, about the too strong upwelling in ERA-Interim and

2. - I found some of the discussion of the regression modeling confusing, and would appreciate if like $Q B O$ amplitude variability that is plotted in figures 7 through 9 . This is not really well defined in the paper. 1 ' $m$ guessing it might be the $Q B O$ coefficient in the regression fit, or it might be the zonit wind fitd as ins wind at $50 \mathrm{hPa}$ ), which is a bit odd and requires a bit more nuanced interpretation. When doing something like this, the correlations at a higher level (at, say, $30 \mathrm{hPa}$ ) aren't really "caused" by he QBO results could be clarified on this point

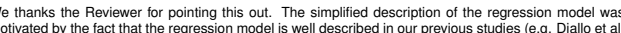
2018,2019 ). Our regression model uses a lag term, therefore, allowing us to use only one QBO prox,

Interactive

comment

Fig. 1. 